\title{
The effect of prestrain on stress assisted two way shape memory effect in a $\mathrm{Ni}_{45} \mathrm{Ti}_{50} \mathrm{Cu}_{5}$ alloy
}

\author{
L. Omodei, G. Gomarasca ${ }^{1}$ and G. Airoldi ${ }^{1,2}$
}

Dipartimento di Fisica, Università di Milano, Via Celoria 16, 20133 Milano, Italy

${ }^{1}$ Istituto Nazionale per la Fisica della Materia (INFM), Dipartimento di Scienza dei Materiali, Università di Milano Bicocca, Via R. Cozzi 53, 20125 Milano, Italy

${ }^{2}$ Dipartimento di Scienza dei Materiali, Università di Milano Bicocca, Via R. Cozzi 53, 20125 Milano, Italy

\begin{abstract}
Stress Assisted Two Way Memory Effect (SATWME) and Electrical Resistance (ER) have been investigated on a $\mathrm{Ni}_{45} \mathrm{Ti}_{50} \mathrm{Cu}_{5}$ alloy preliminarily prestrained in martensite to modify the critical stress for slip. Different prestrain levels have been applied.

ER vs $\varepsilon$ during SATWME follows an almost linear relationship across the transformation range: the plastic deformation accumulated during cycling generally increases, but the figure of $\varepsilon_{\mathrm{P}}$ lowers with increasing the preliminary prestrain.

Even the highest applied prestrain $(\approx 15 \%)$ does not allow to eliminate the build up of plastic strain in each cycle. Different procedures to modify the critical stress for slip must be envisaged.
\end{abstract}

\section{INTRODUCTION}

$\mathrm{Ni}_{(50-x)} \mathrm{Ti}_{50} \mathrm{Cu}_{\mathrm{x}}$ is an attractive alloy system for several different features: for low $\mathrm{x}$ values one Thermoelastic Martensitic Transformation (TMT) $B 2-B 19^{\prime}$ is present. For intermediate $x$ values $(6.7<\mathrm{x}<15)$ two transformations B2-B19 and B19-B19' dominate, whilst for $\mathrm{x}>15$ just the B2-B19 is present [1].

The presence of one single transformation for $x=5$ with a narrower hysteresis width in comparison to the binary NiTi has stimulated its use in the study both of the Stress Assisted Two Way Memory Effect (SATWME) and of the Electrical Resistance (ER) across the transformation range with the aim to assess the sensing/actuating capabilities.

Some literature results on SATWME for a $\mathrm{Ni}_{40} \mathrm{Ti}_{50} \mathrm{Cu}_{10}$ alloy [2] submitted to constant stress states higher than $70 \mathrm{MPa}$, pointed out high elongations in martensite and plastic deformation built in each cycle, which heavily compromises the use as actuator.

In a previous paper [3], present authors presented preliminary results obtained on a $\mathrm{Ni}_{45} \mathrm{Ti}_{50} \mathrm{Cu}_{5}$ alloy investigating SATWME and ER across the transformation range: even under a low stress level, smaller than the macroscopic reorientation stress in martensite, a plastic deformation $\varepsilon_{P}$ is accumulated with cycling. Since the critical stress for slip appears as the true critical limitation factor in the actuator field, investigations were here performed on $\mathrm{Ni}_{45} \mathrm{Ti}_{50} \mathrm{Cu}_{5}$ alloys preliminarily pre-strained in martensite to increase the critical stress for slip. Pre-strains up to $15 \%$, as below explained, were applied before investigating SATWME under an applied constant stress state of $75 \mathrm{MPa}$.

\section{EXPERIMENTAL}

Measurements were carried out on wires of nominal composition $45 \mathrm{at} \% \mathrm{Ni}-50 \mathrm{at} \% \mathrm{Ti}-5 \mathrm{at} \% \mathrm{Cu}$ with roughly $26 \%$ cold work. The wire diameter was $300 \mu \mathrm{m}$ and the gauge lenghts ranged from $50 \mathrm{~mm}$ to $80 \mathrm{~mm}$ depending on the test. 
The specimens were submitted to a TT of $1.80 \mathrm{ks}$ at $773 \mathrm{~K}$ followed by preliminary prestrain. Pre-strains were applied in strain control mode at room temperature, in martensitic phase. In each pre-strain step the specimens were submitted to a fixed total applied strain; after unloading the pseudoplastic strain was partially recovered by heating up to a temperature higher than the transformation finish parent phase temperature. The strain left unrecovered is the plastic pre-strain $\varepsilon_{\mathrm{ps}}$. The above sequence was repeated up to different $\varepsilon_{\mathrm{ps}}$ values of $5,9,11,13$ and $15 \%$.

Thermal cycling was performed by means of an applied electrical current finely tuned through an ad hoc developed program. Data acquisition, storage and handling were computer controlled.

SATWME and the Normalized Electrical Resistance change (NER) across the transformation range were investigated under a $75 \mathrm{MPa}$ constant stress state following the procedure described in a previous paper [4]: the stress state was applied at start in parent phase to promote the best oriented martensite phase on decreasing temperature. Up to 700 cycles were performed.

The actual applied stress, monitored during each cycle, is constant within $\pm 3 \%$. All the tests were performed at ambient temperature of roughly $293 \mathrm{~K}$. Special grippers were machined with a running water cooling circuit in order to guarantee the temperature is stable in each cycle.

\section{RESULTS}

The transformation temperatures for zero stress were determined by DSC plotted in figure 1; it can be appreciated the presence of one single transformation with $\mathrm{M}_{\mathrm{f}}, \mathrm{M}_{\mathrm{s}}, \mathrm{A}_{\mathrm{s}}$, $\mathrm{A}_{\mathrm{f}}$ respectively $308 \mathrm{~K}, 314 \mathrm{~K}$, $325 \mathrm{~K}, 332 \mathrm{~K}$.

Current driven $\mathrm{Ni}_{45} \mathrm{Ti}_{50} \mathrm{Cu}_{5}$ wires under a constant stress of $75 \mathrm{MPa}$ were examined under different start conditions related to the preliminarily introduced pre-strain: the applied investigated prestrains were 5,9 , 11,13 and $15 \%$.

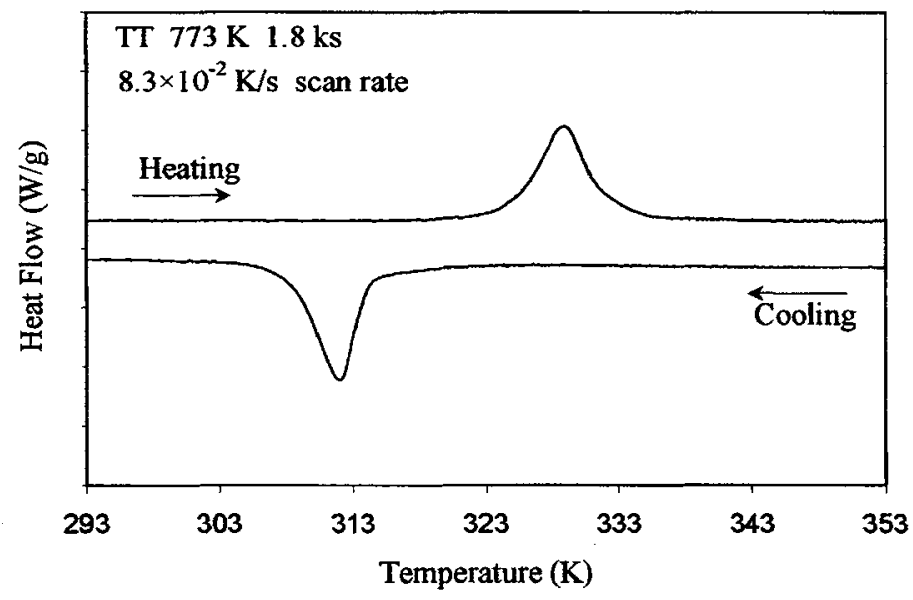

Fig. 1. DSC scans showing B2-B19' transformation sequence

The sequences of thermal cycles under a constant stress of $75 \mathrm{MPa}$ for strain vs current density curves performed on the specimens, with no pre-strain and with a pre-strain of either 9 or $13 \%$, are plotted in fig. 2. The Normalized ER vs current density curves related to the same thermal cycles are given in fig.3. A similar behaviour was found for specimens submitted to 5,11 and $15 \%$ pre-strain.

The NER vs strain deduced from previous plots, given in figure 2 and 3, are shown in fig.4: a large shift was introduced by cycling when no prestrain was applied. The shift decreases with increasing the prestrain.

The SATWME, deduced as shown in figure 2, are plotted in figure 5 as a function of the cycle number for each pre-strain value. 

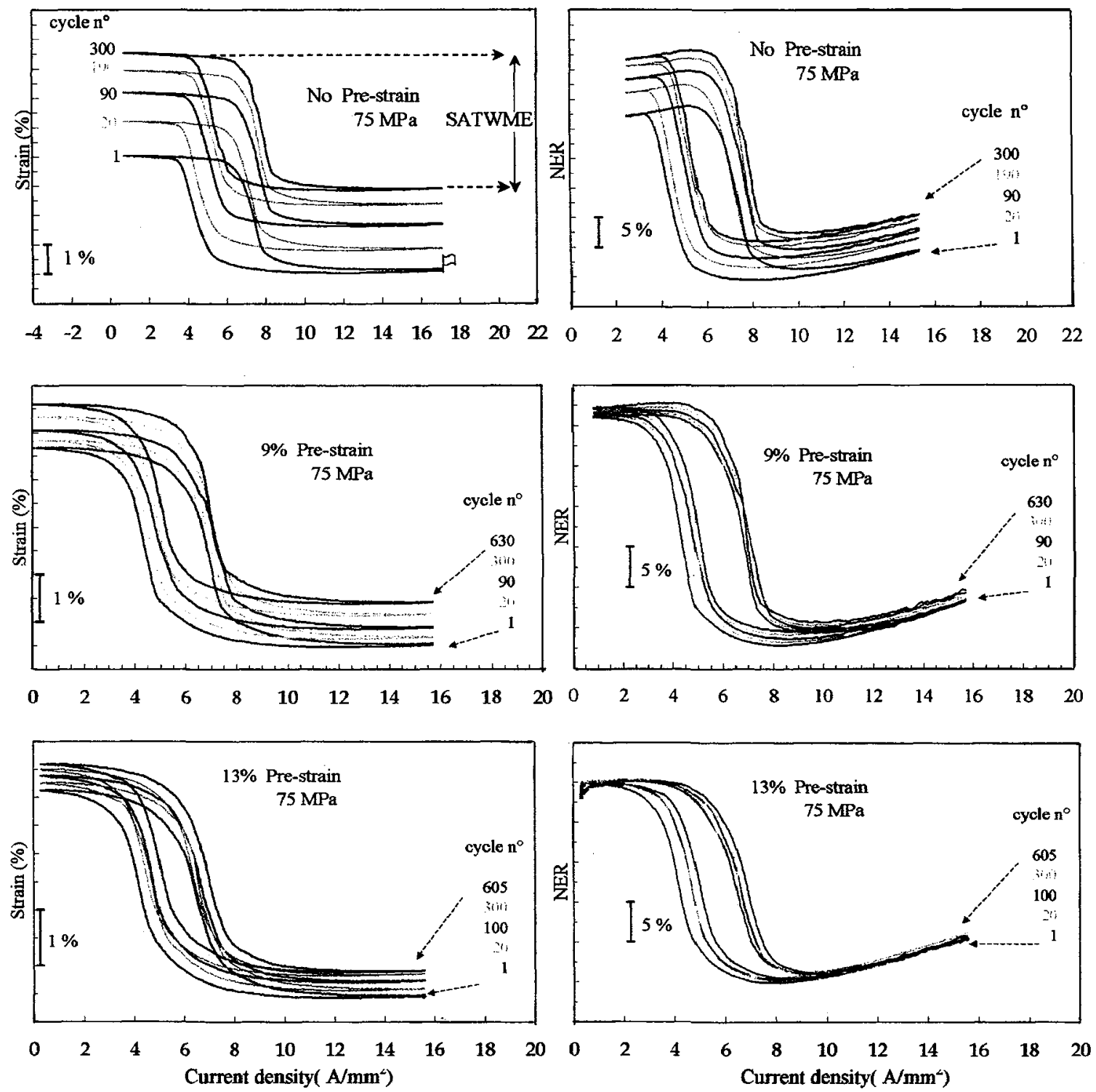

Fig. 2. Strain vs current density during the cycles for different start conditons. The flag gives the start point of the curves.

Fig. 3. NER vs current density during the cycles for different start conditons.

\section{DISCUSSION}

Strain generally increases with cycling: some plastic strain is built in the specimens as a consequence of $\mathrm{M} \leftrightarrow \mathrm{P}$ transformation under stress. That is clearly shown in figure 2 where just some cycles are shown: the strain increase lowers with cycling on pre-strained specimens as proved by the data plotted for specimens with 9 and $13 \%$ pre-strain. 

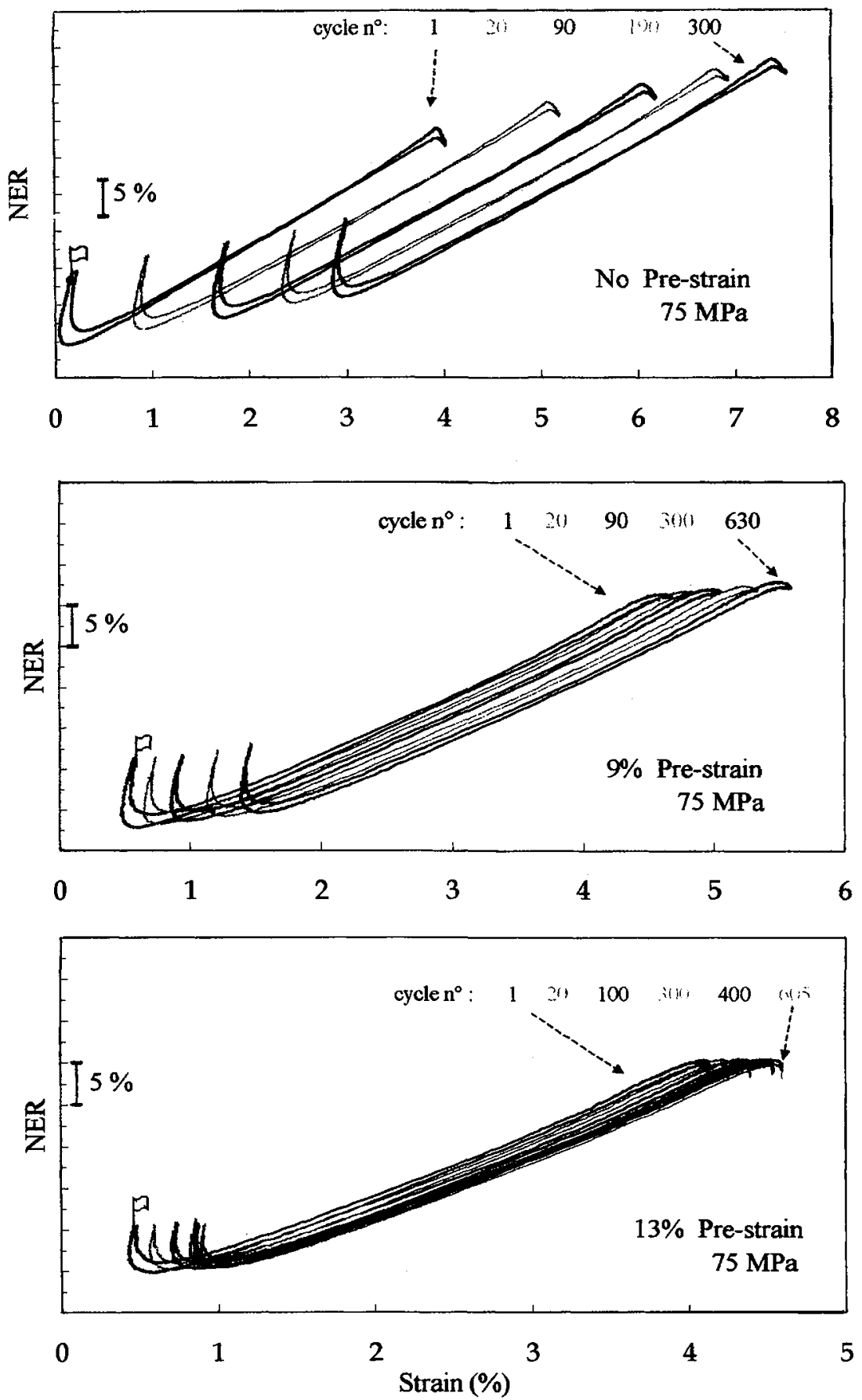

Fig. 4. NER vs strain during the cycles on thermally treated specimens under an applied stress of 75 MPa. Data show the incidence of prestrain on ER vs $\varepsilon$ curves. The flags give the start point of the curves. 


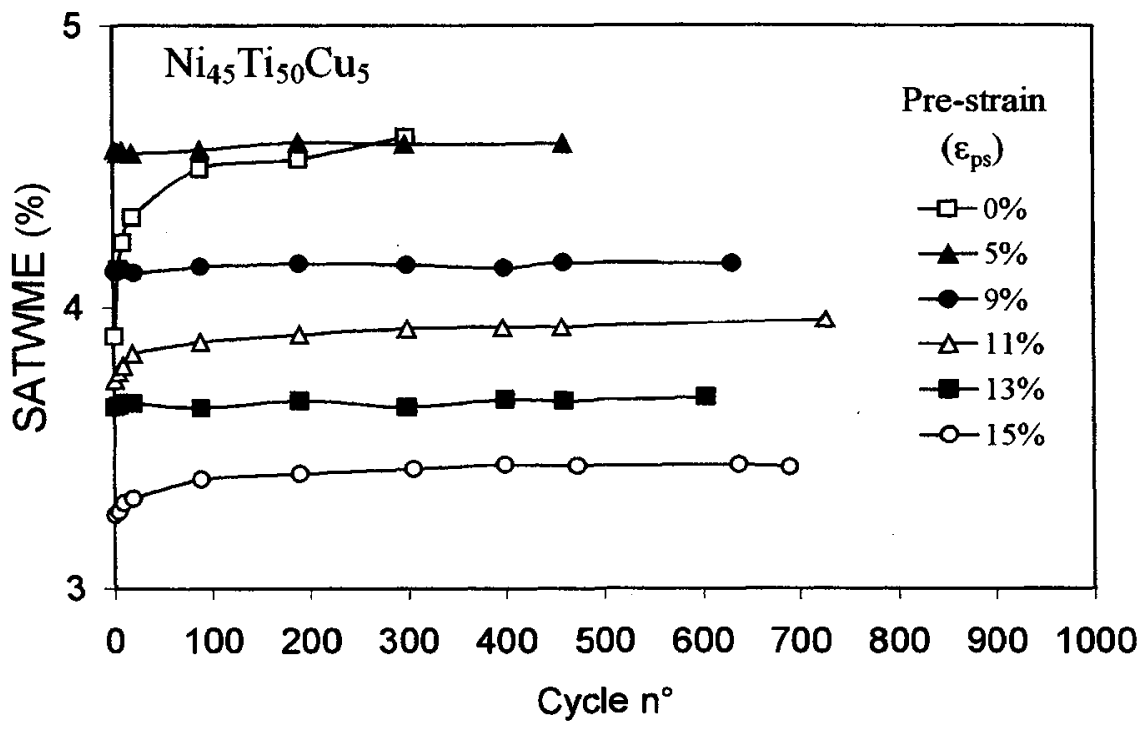

Fig. 5. SATWME under the applied stress of $75 \mathrm{MPa}$ for all the performed cycles on $\mathrm{Ni}_{45} \mathrm{Ti}_{50} \mathrm{Cu}_{5}$ at different prestrains.

A total plastic strain $\varepsilon_{\mathrm{p}}$ can be evaluated from the strain values at the maximum applied current density, at high temperature, in comparison to the start strain value.

The total plastic strain built in with cycling is plotted in fig. 6 for all the investigated specimens: it can be appreciated the big increase of $\varepsilon_{p}$ with cycling when no pre-strain is applied and the slower increase when a pre-strain is preliminarily applied. Higher is the applied pre-strain, lower is the total plastic strain accumulated with cycling. $\varepsilon_{\mathrm{p}}$ remarkably lowers with increasing the preliminary prestrain $\varepsilon_{\mathrm{ps}}$, though even the highest prestrain does not allow to eliminate the build up of plastic deformation.

It can be seen that both SATWME values and $\varepsilon_{p}$, left after recovery, increase with the thermal cycle number though with different rates for a fixed pre-strain (fig. 5,6 ).

SATWME generally decreases with the increase of the imprinted pre-strain. For all the investigated prestrains the SATWME increases during the first twenty cycles and is almost constant up to the highest number of tested cycles, despite the increase in the accumulated $\varepsilon_{\mathrm{p}}$ with cycling.

An interesting feature is related to NER results: NER vs $\varepsilon$ appear almost linear for all the start conditions and the rates $d(N E R) / d \varepsilon$ are almost unmodified by prestrain: that is clearly shown either in figure 4 , where Normalized Electric Resistance vs $\varepsilon$ is given during thermal cycles, or in Tab.1, where the values of rates are given for all the performed test.

The pre-strain can considerably reduce the plastic strain accumulated during cycling under stress: from $\varepsilon_{\mathrm{p}}=2.8 \%$ introduced after 300 cycles without pre-strain, $\varepsilon_{\mathrm{p}}=0.2 \%$ is found for a preliminary pre-strain of $15 \%$. SATWME is however reduced from $4.6 \%$ to $3.4 \%$.

Table 1

\begin{tabular}{|c|c|c|c|c|}
\hline Prestrain $=\varepsilon_{\mathrm{ps}}(\%)$ & SATWME (\%) & $\mathrm{d}(\mathrm{ER}) / \mathrm{d} \varepsilon$ & Total $\varepsilon_{\mathrm{p}}(\%)$ & Cycle number \\
\hline 0 & & & & \\
\hline 5 & 4.6 & 7.3 & 2.8 & 300 \\
\hline 9 & 4.5 & 7.6 & 0.9 & 460 \\
\hline 11 & 4.1 & 7.4 & 0.9 & 632 \\
\hline 13 & 3.9 & 7.6 & 0.8 & 727 \\
\hline 15 & 3.7 & 7.2 & 0.5 & 605 \\
\hline & 3.4 & 7.2 & 0.2 & 690 \\
\hline
\end{tabular}




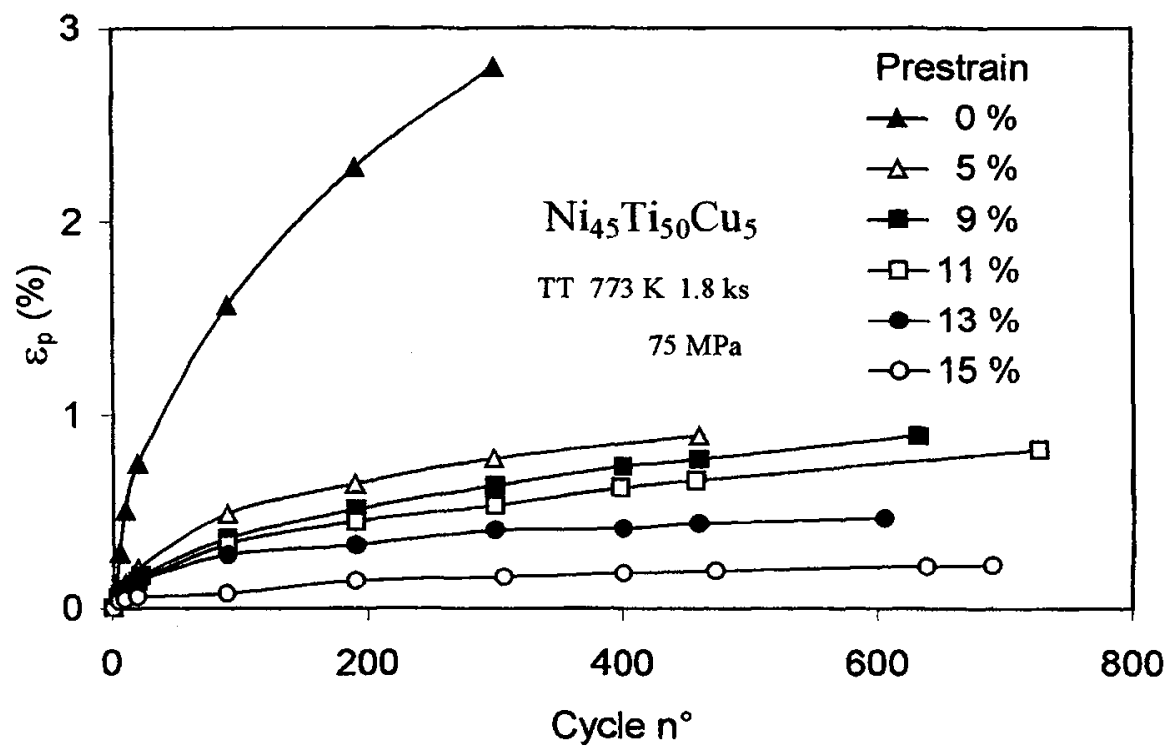

Fig. 6. Total $\varepsilon_{\mathrm{p}}$ for all the performed cycles on all the prestrained $\mathrm{Ni}_{45} \mathrm{Ti}_{50} \mathrm{Cu}_{5}$ alloys.

\section{CONCLUSIONS}

At the light of results here obtained it can be concluded:

- Pre-strains applied in martensitic phase on $\mathrm{Ni}_{45} \mathrm{Ti}_{50} \mathrm{Cu}_{5}$ can considerably reduce the plastic strain accumulated during cycling under stress.

- Pre-strains reduce also the SATWME values: however just a $25 \%$ reduction is found for the highest prestrain here investigated

- A modification of the critical stress for slip is the key factor to reduce the shift in strain of NER vs $\varepsilon$ curves with cycling.

- Different preliminary TT and/or cold work apt to eliminate this drawback should be investigated

\section{ACKNOWLEDGMENTS}

The support of I.N.F.M. (Istituto Nazionale per la Fisica della Materia) is gratefully acknowledged.

1] Nam T.H., Saburi T., Shimizu K., Materials Transactions, JIM, Vol. 31, No.11 (1990), pp. 959 to 967

2] Zadno R., Simpson J.W., Imran M.A., in Proc. $1^{\text {st }}$ Int.Conf.SMST-94, ed. A.R.Pelton, D.Hodgson, T.Duerig, (Library of Congress Catalog 1994), pg.317

3] Airoldi G., Gomarasca G., Omodei L., in Proc. $1^{\text {st }}$ Eur. Conf. on Shape Memory and Superelastic Technologies, Antwerp, 5-9 sept.1999, B, edited by W.Van Moorleghem, P.Besselink, D.Aslanidis, (SMST Europe 1999), p.75-81

4] M.Pozzi, G.Airoldi, Mat.Sc. and Eng. A273-275, 300-304, (1999) 